\title{
Liquid Phase Synthesis of CoP Nanoparticles with High Electrical Conductivity for Advanced Energy Storage
}

\author{
Guo-Qun Zhang, ${ }^{1,2}$ Bo Li, ${ }^{1,2}$ Mao-Cheng Liu, ${ }^{1,2}$ Shang-Ke Yuan, ${ }^{3}$ and Leng-Yuan Niu' \\ ${ }^{1}$ State Key Laboratory of Advanced Processing and Recycling of Non-Ferrous Metals, Lanzhou University of Technology, \\ Lanzhou 730050, China \\ ${ }^{2}$ School of Materials Science and Engineering, Lanzhou University of Technology, Lanzhou 730050, China \\ ${ }^{3}$ College of Civil Engineering, Lanzhou Institute of Technology, Lanzhou 730050, China \\ Correspondence should be addressed to Mao-Cheng Liu; liumc@lut.cn
}

Received 2 June 2017; Revised 21 August 2017; Accepted 5 September 2017; Published 9 October 2017

Academic Editor: Syam Sundar

Copyright (c) 2017 Guo-Qun Zhang et al. This is an open access article distributed under the Creative Commons Attribution License, which permits unrestricted use, distribution, and reproduction in any medium, provided the original work is properly cited.

\begin{abstract}
Transition metal phosphide alloys possess the metalloid characteristics and superior electrical conductivity and are a kind of high electrical conductive pseudocapacitive materials. Herein, high electrical conductive cobalt phosphide alloys are fabricated through a liquid phase process and a nanoparticles structure with high surface area is obtained. The highest specific capacitance of $286 \mathrm{~F} \mathrm{~g}^{-1}$ is reached at a current density of $0.5 \mathrm{~A} \mathrm{~g}^{-1} .63 .4 \%$ of the specific capacitance is retained when the current density increased 16 times and $98.5 \%$ of the specific capacitance is maintained after 5000 cycles. The AC//CoP asymmetric supercapacitor also shows a high energy density ( $21.3 \mathrm{Wh} \mathrm{kg}^{-1}$ ) and excellent stability ( $97.8 \%$ of the specific capacitance is retained after 5000 cycles). The study provides a new strategy for the construction of high-performance energy storage materials by enhancing their intrinsic electrical conductivity.
\end{abstract}

\section{Introduction}

Supercapacitors exhibit high power density, fast charging, and long cycling life; they have potential applications in electronic devices, hybrid electric vehicles, and military devices [1-3]. However, the energy density of supercapacitors (4-5 $\mathrm{Wh} \mathrm{kg}^{-1}$ for carbon based supercapacitors) is still lower than batteries (30-60 $\mathrm{Wh} \mathrm{kg}^{-1}$ ) and prevents their practical applications $[4,5]$. Therefore, many researchers are focused on improving the energy density of supercapacitors while maintaining their high power density [6-8]. The energy storage of pseudocapacitors is based on the Faraday reactions occurring at the surface of electroactive materials, such as $\mathrm{RuO}_{2}, \mathrm{MnO}_{2}, \mathrm{IrO}_{2}$, and $\mathrm{Co}_{3} \mathrm{O}_{4}$ [9-13], and the energy density is higher than carbon based electric double-layer capacitors. Transition metal oxides provide higher specific capacitance and energy density than carbon materials $[14,15]$, which have been considered as promising pseudocapacitive materials.
Among transition metal oxides, cobalt oxides are widely studied as pseudocapacitive materials due to their high specific capacitance, excellent rate capability, and good cycle stability [16-18]. However, the cobalt oxides still suffer from poor electrical conductivity which limits charge/discharge performance at larger current densities $[19,20]$. The general strategy for improving conductivity of cobalt oxides is compositing them with high electrical conductive carbons or graphene. For example, $\mathrm{Co}_{3} \mathrm{O}_{4}$-reduced graphene oxide scrolls [21], ordered mesoporous carbon composite films containing cobalt oxide and vanadia [22], nitrogen doping graphene based cobalt oxide [23], multiwalled carbon nanotubes, and cobalt oxide film [24] have been fabricated and exhibited better performance than pure cobalt oxide due to the improved electrical conductivity. Unfortunately, the electrical conductivity improvement of adding carbons is limited and the specific capacitance will be decreased when too much carbon is added (because carbon materials 
would not contribute pseudocapacitance to the composite materials) [25]. Therefore, it is important to look for a new strategy for improving conductivity of cobalt based pseudocapacitive materials. Interestingly, cobalt phosphides possess the metalloid characteristics and superior electrical conductivity $\left(3.17 \mathrm{~S} \mathrm{~cm}^{-1}\right.$ compared with $10^{-4}$ to $10^{-2}$ of $\left.\mathrm{Co}_{3} \mathrm{O}_{4}\right)[26,27]$ and are a promising high electrical conductive electrode material of pseudocapacitors. This is because both of the oxidized and reduced cobalt exist in the cobalt phosphide alloys, rather than only oxidized cobalt in the cobalt oxides. The oxidized cobalt in cobalt phosphides could store charges and provide high capacitance through Faradaic reactions, while the reduced cobalt could provide free electrons and greatly improve electrical conductivity. This means that cobalt phosphides will not only possess high capacitance, but also provide high electrical conductivity and excellent rate capability. This inspires us to study the pseudocapacitive performance of high electrical conductive cobalt phosphide alloys.

Because of the high electrical conductivity, cobalt phosphides have been studied as materials of lithium ion batteries $[28,29]$ and supercapacitors [30]. For example, Wang and coworkers [30] have proved that $\mathrm{Co}_{2} \mathrm{P}$ is an ideal supercapacitive material with good cycle performance and high specific capacity. The study indicates that cobalt phosphide is a promising high electrical conductivity energy storage material. This inspires us to further design and study the electrochemical properties of cobalt phosphide with other crystal phases.

Herein, high electrical conductivity CoP nanoparticles with a triangular-pyramid-like structure are further synthesized through a liquid phase process using cobalt acetylacetonate as cobalt precursor and trioctylphosphine as phosphorus source. They show ideal pseudocapacitive properties; the highest specific capacitance is $286 \mathrm{~F} \mathrm{~g}^{-1}$ at a current density of $0.5 \mathrm{~A} \mathrm{~g}^{-1} \cdot 63.4 \%$ of the specific capacitance is retained when the current density increased 16 times and $98.5 \%$ of the specific capacitance is maintained after 5000 cycles. The $\mathrm{AC} / / \mathrm{CoP}$ asymmetric supercapacitor was assembled using $\mathrm{CoP}$ as the positive electrode and activated carbon as the negative electrode which also shows a high energy density $\left(21.3 \mathrm{Wh} \mathrm{kg}^{-1}\right)$ and an excellent stability ( $97.8 \%$ of the specific capacitance is retained after 5000 cycles). The study manifests that $\mathrm{CoP}$ alloys are ideal pseudocapacitive materials and have great potential for high-performance electrochemical energy storage systems.

\section{Experimental Section}

$\mathrm{CoP}$ particles were synthesized through a liquid phase reaction. $0.5 \mathrm{~g}$ cobalt acetylacetonate (purity $98 \%$, shanghai Macklin Biochemical Co., Ltd.), $5 \mathrm{ml}$ of 1-octadecene (purity 90\%, SA Chemical Technology (Shanghai) Co., Ltd.), and $0.3 \mathrm{ml}$ of trioctylphosphine (purity $90 \%$, SA Chemical Technology (Shanghai) Co., Ltd.) were added in a three-necked round-bottomed flask. Then the mixture was stirred at $300^{\circ} \mathrm{C}$ for $5 \mathrm{~h}$. After cooling to room temperature, the sample was washed with normal hexane several times and dried at $80^{\circ} \mathrm{C}$ for $12 \mathrm{~h}$ in vacuum oven. The structure characterizations, electrochemical evaluations, and the preparation of the CoP electrodes are shown in supporting information.

\section{Results and Discussions}

Cobalt and phosphorus atoms arose from the thermal decomposition of cobalt acetylacetonate and trioctylphosphine during the liquid phase reaction, and then $\mathrm{CoP}$ particles are formed through the combination between cobalt and phosphorus atoms. Figure 1(a) shows the X-ray diffraction (XRD) pattern of the CoP particles. It is obvious that the pattern of $\mathrm{CoP}$ is corresponding to the standard patterns of CoP (PDF, card number 29-0497). The diffraction peaks located at $31.62^{\circ}, 34.56^{\circ}, 36.34^{\circ}, 47.74^{\circ}, 56.70^{\circ}, 63.06^{\circ}, 67.95^{\circ}$, and $77.06^{\circ}$ can be indexed as (011), (200), (111), (211), (301), (311), (220), and (222) planes of CoP, respectively. The sharp peaks indicate the high crystallinity that is favorable for the CoP to exhibit a high electrical conductivity and even excellent rate capability. However, the XRD pattern of the sample also shows the presence of $\mathrm{Co}_{2}\left(\mathrm{P}_{4} \mathrm{O}_{12}\right)$ (PDF, card number 86-2161) in the sample. The low content of $\mathrm{Co}_{2}\left(\mathrm{P}_{4} \mathrm{O}_{12}\right)$ phase may be formed through the oxidation of $\mathrm{CoP}$. X-ray photoelectron spectroscopy (XPS) is used to investigate the chemical bonding states of $\mathrm{Co}$ and $\mathrm{P}$ in cobalt phosphide. The survey spectrum of $\mathrm{CoP}$ (as shown in Figure 1(b)) contains the peaks of $\mathrm{Co}, \mathrm{P}, \mathrm{C}$, and $\mathrm{O}$ elements, where the $\mathrm{C}$ element is added as master standard for peak position calibration and the $\mathrm{O}$ element is derived from surface adsorption of sample when exposed to the air. Figure $1(\mathrm{c})$ is the Co $2 \mathrm{p}$ spectrum. The peaks at binding energy of $781.3 \mathrm{eV}$ and $797.2 \mathrm{eV}$ can be assigned to the Co $2 p_{3 / 2}$ and Co $2 p_{1 / 2}$ peaks of oxidized $\mathrm{Co}^{2+}$ [31], while the peaks at $778.9 \mathrm{eV}$ and $794.5 \mathrm{eV}$ are corresponding to the $\operatorname{Co} 2 \mathrm{p}_{3 / 2}$ and $\mathrm{Co} 2 \mathrm{p}_{1 / 2}$ peaks of reduced Co [32]. Besides, the peaks located at $786.0 \mathrm{eV}$ and $803.1 \mathrm{eV}$ are satellites peaks (denoted as "Sat."). The results indicate that there are two kinds of cobalt (the oxidized $\mathrm{Co}^{2+}$ and the reduced Co) existing in the $\mathrm{CoP} . \mathrm{Co}^{2+}$ will be oxidized to $\mathrm{Co}^{3+}$ during the electrode reaction process, which contributes specific capacitance to the CoP electrode, while the reduced Co will provide free electrons and greatly improve electrical conductivity of CoP. It is suggested that the CoP will not only possess high capacitance, but also provide high electrical conductivity, which will serve as an ideal electrode material for pseudocapacitors.

The surface morphology and microstructure are shown in Figure 2. It can be seen from the scanning electron microscopy (SEM) image (Figure 2(a)) that the CoP exhibits a loosely packed nanoparticles structure and there are abundant interspaces existing between the nanoparticles. This result can further be shown as transmission electron microscope (TEM) image in Figure 2(b). The CoP nanoparticles show a triangular-pyramid-like structure and the size of triangular-pyramid-like nanoparticles is about $20-30 \mathrm{~nm}$. The small size of the CoP nanoparticles will introduce a larger surface area and provide more active 

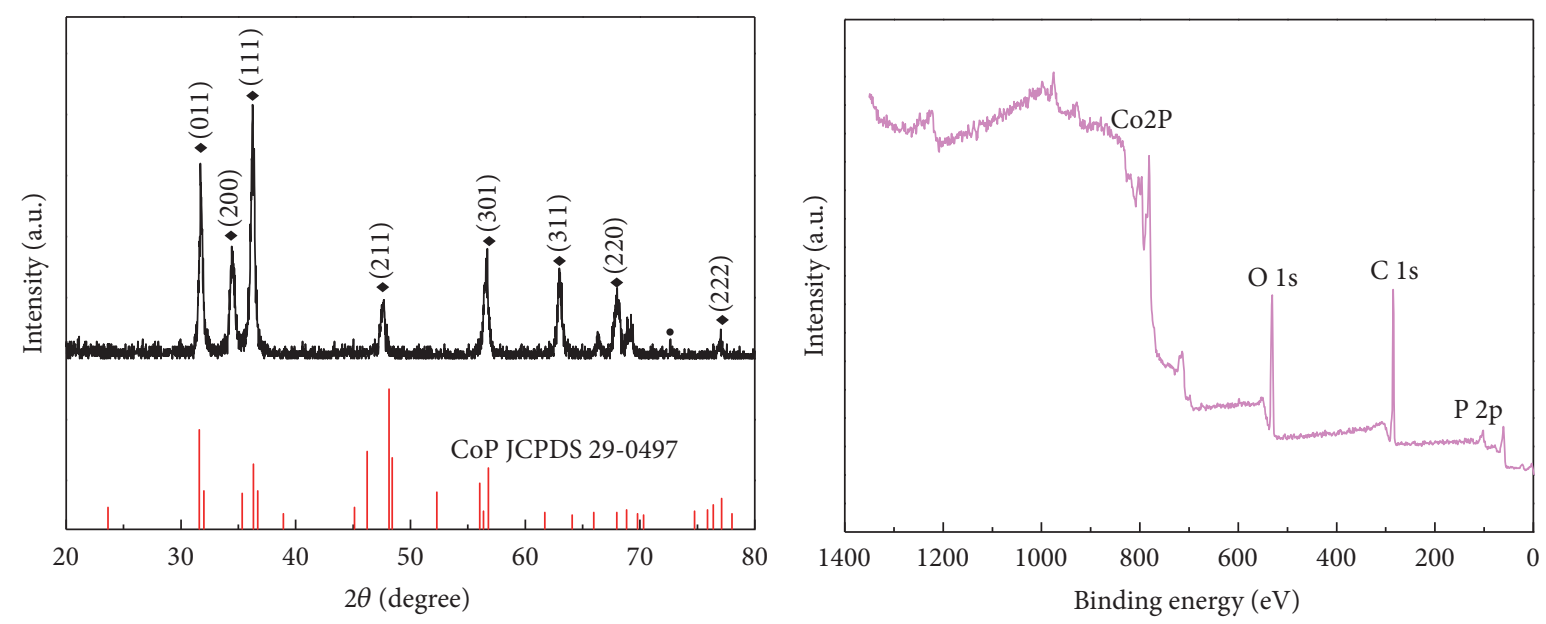

- $\mathrm{CoP}$

- $\mathrm{Co}_{2}\left(\mathrm{P}_{4} \mathrm{O}_{12}\right)$

(a)

(b)

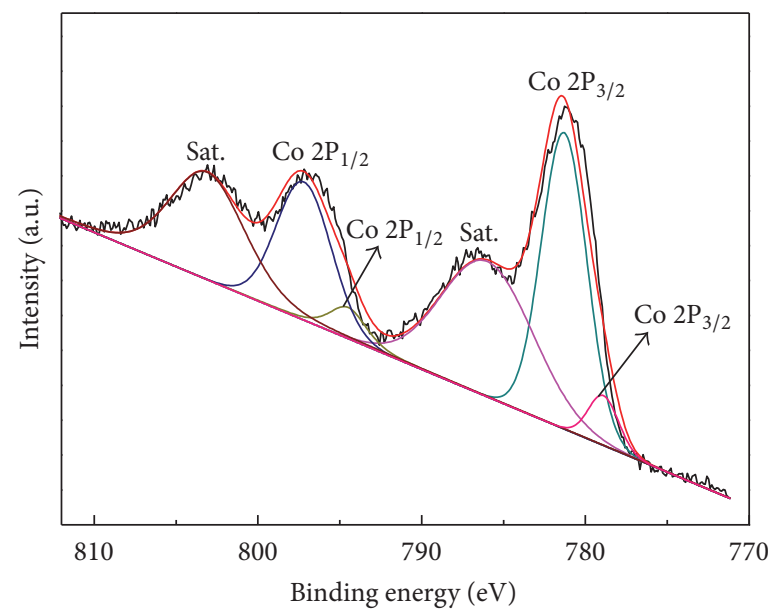

(c)

Figure 1: (a) XRD pattern of CoP particles. XPS spectra of the CoP (b) survey spectrum and (c) Co 2p.

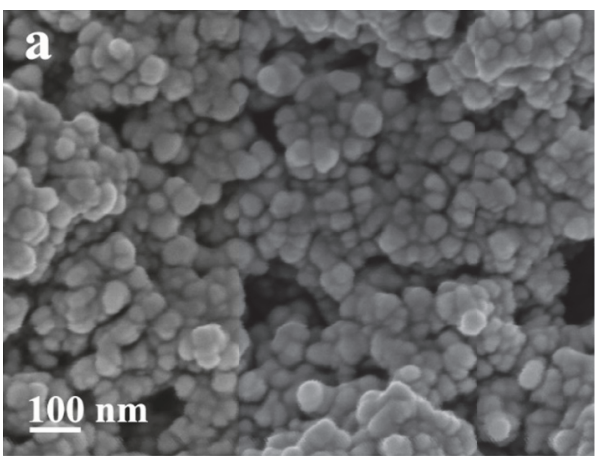

(a)

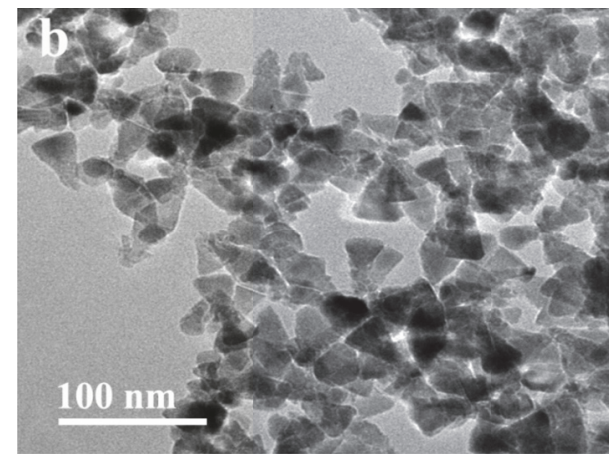

(b)

FIgURE 2: (a) SEM image and (b) TEM image of CoP particles. 

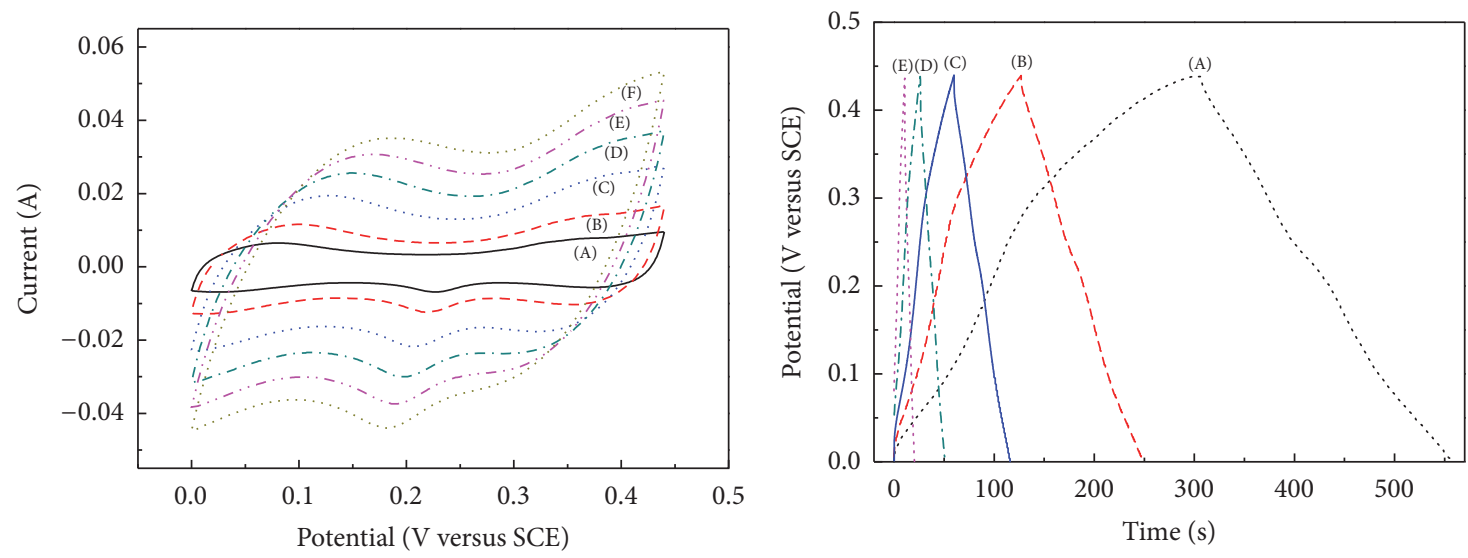
(A) $5 \mathrm{mV} \mathrm{s}^{-1}$
(B) $10 \mathrm{mV} \mathrm{s}^{-1}$
(D) $30 \mathrm{mV} \mathrm{s}^{-1}$
(C) $20 \mathrm{mV} \mathrm{s}^{-1}$
(E) $40 \mathrm{mV} \mathrm{s}^{-1}$
(F) $50 \mathrm{mV} \mathrm{s}^{-1}$

(a)
(A) $0.5 \mathrm{Ag}^{-1}$
(B) $1 \mathrm{Ag}^{-1}$
(D) $4 \mathrm{Ag}^{-1}$
(C) $2 \mathrm{Ag}^{-1}$
(E) $8 \mathrm{Ag}^{-1}$

(b)

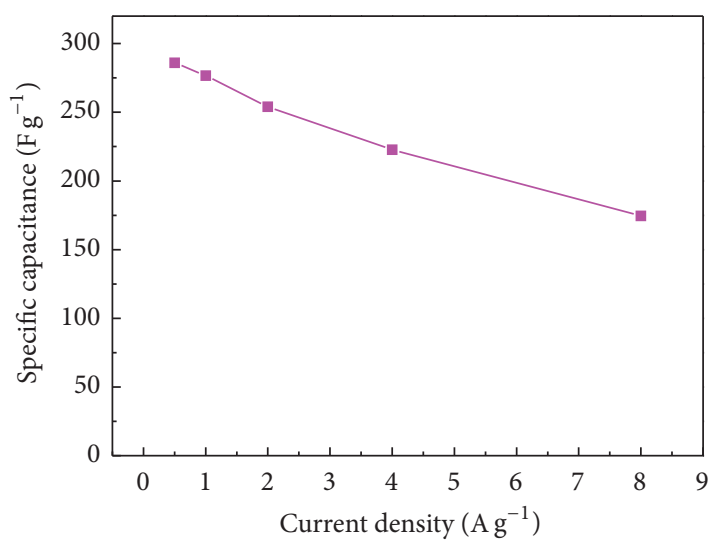

(c)

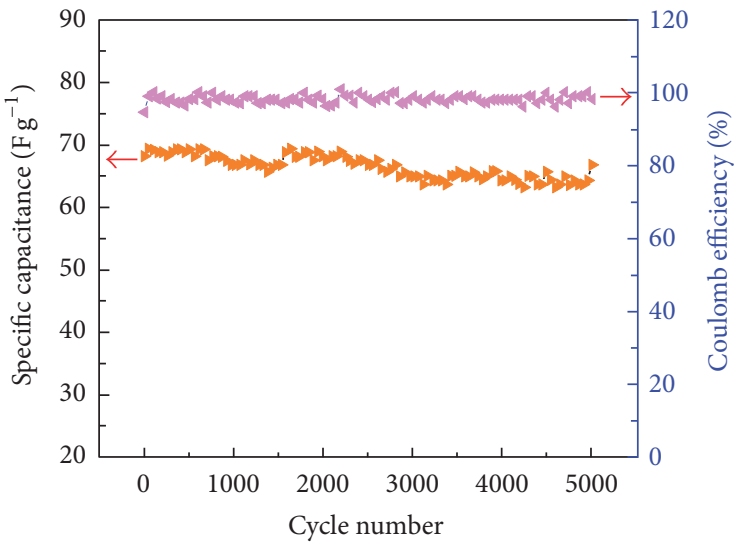

(d)

Figure 3: Pseudocapacitive properties of CoP electrode. (a) CV curves at different scan rates, (b) charge/discharge curves at various current densities, (c) specific capacitance at different current densities, and (d) cycling stability at $2 \mathrm{~A} \mathrm{~g}^{-1}$.

sites for the Faraday reactions during charge/discharge process, which will contribute a high specific capacitance. The TEM image also indicates the existence of the interspaces between triangular-pyramid-like nanoparticles. This will provide convenient transportation channels for electrolyte ions and lead to excellent rate capability. The results indicate that the CoP exhibits an ideal morphology and microstructure to serve as pseudocapacitive materials. The porous structure is further characterized by the nitrogen adsorption/desorption experiment (the nitrogen adsorption/desorption isotherms and pore size distribution of CoP are shown in Figure S1 in Supplementary Material available online at https://doi.org/10.1155/2017/9728591). The results indicate that the CoP nanoparticles show a high surface area of $35.4 \mathrm{~m}^{2} \mathrm{~g}^{-1}$. It is necessary to possess a large electrode specific surface area for improving the specific capacitances.

Figure 3(a) shows the CV curves of CoP nanoparticles electrode. The weak redox peaks are observed in each curve, suggesting that the capacitance of CoP electrode is mainly based on the redox mechanism. It is obvious that the shapes of CV curves are close to quasi-rectangular and their enclosed areas are almost distributed in the whole potential window. This means that the surface Faraday reactions of CoP can occur at the whole potential window, suggesting its ideal pseudocapacitive properties. The shape of the CV curves is not significantly influenced by the increase of the scan rates. This indicates the improved mass transportation and electron conduction in the host materials. The fast mass transportation of electrolyte ions to the surface of the CoP electrode could be ascribed to the abundant interspaces between the nanoparticles which provide convenient diffusion channels for electrolyte ions transportation, while the fast electron conduction in the host materials will be attributed to the high electronic conductivity of the CoP. Both the fast mass transportation of electrolyte ions to the surface of the electrode and fast electron conduction in the 
host materials are beneficial to improve the rate capability of the CoP electrode. To further understand the rate capability and calculate the specific capacitance of the CoP electrode, charge/discharge measurements were performed at various current densities, as shown in Figure 3(b). The curves have a shape like an isosceles triangle that indicates its ideal capacitive behavior. This result is also in accordance with the CV curves. Figure 3(c) exhibits the specific capacitance of the CoP electrode calculated according the discharge curves from the following equation:

$$
C_{m}=\frac{I \times \Delta t}{\Delta V \times m}
$$

where $C$ is the total capacitance, $I$ is the discharge current, $\Delta t$ is the discharge time, $\Delta V$ represents the potential window, $C_{m}$ is the specific capacitance, and $m$ is the mass of active materials. The specific capacitance of the $\mathrm{CoP}$ electrode is $286 \mathrm{Fg}^{-1}$ at a discharge current density of $0.5 \mathrm{Ag}^{-1}$ and remains $175 \mathrm{~F} \mathrm{~g}^{-1}$ when the current density is increased to $8 \mathrm{~A} \mathrm{~g}^{-1}$. Though the specific capacitances gradually decreased at higher current density due to the incremental (IR) voltage drop and insufficient active materials being involved in the redox reaction at higher current, $63.4 \%$ of the specific capacitance is still retained when the current density increased 16 times that shows excellent rate capability. This is attributed to the fast mass transportation of electrolyte ions to the surface of the CoP electrode and the fast electron conduction in the host materials of CoP. The cycling stability of the CoP nanoparticles electrode is demonstrated in Figure 3(d). The specific capacitance for the first cycle is $224 \mathrm{Fg}^{-1}$ and then gradually increased in the later cycles due to the fully electrochemical activation of the CoP electrode. Interestingly, the specific capacitance of $\mathrm{CoP}$ electrode reached the highest value of $272.2 \mathrm{~F} \mathrm{~g}^{-1}$ at 2000 cycles and no visible decrease of specific capacitance was found after 5000 cycles. Besides, the coulomb efficiency of the CoP electrode reached 98.5\% during 5000 cycles and indicated excellent reversibility of the CoP. Combined with the high specific capacitance, excellent stability, and rate capability, the as-prepared $\mathrm{CoP}$ is an ideal material for pseudocapacitors.

For further evaluation of the properties of the CoP electrode, an $\mathrm{AC} / / \mathrm{CoP}$ asymmetric supercapacitor was assembled with $\mathrm{CoP}$ as the positive electrode and activated carbon (AC) as the negative electrode. The capacitive performance of AC electrode is shown in Figure S2. It is obvious that the AC electrode exhibits excellent electric double-layer capacitive properties. The specific capacitance reached $206 \mathrm{Fg}^{-1}$ at a discharge current density of $0.5 \mathrm{Ag}^{-1}$. Combined with the specific capacitance and potential window of the CoP electrode, the mass ratio between $\mathrm{CoP}$ and $\mathrm{AC}$ is calculated according to

$$
\frac{m_{+}}{m_{-}}=\frac{C_{-m} \times \Delta V_{-}}{C_{+m} \times \Delta V_{+}}
$$

where $C_{-m}$ and $C_{+m}$ are the specific capacitance of the AC and CoP electrode, $\Delta V$ is potential window, and $m$ is the mass of active materials. The calculated mass ratio of $\mathrm{CoP} / \mathrm{AC}$ is $1: 1.3$. An appropriate voltage window is very important to $\mathrm{AC} / / \mathrm{CoP}$ asymmetric supercapacitor; otherwise there is a risk of damaging the cell when charging it in the high potential. It is considered that the appropriate operation voltage window of $\mathrm{AC} / / \mathrm{CoP}$ asymmetric supercapacitor is 0-1.6 V (Figure S3).

The electrochemical test of the AC//CoP capacitor indicates its excellent properties. It shows quasi-rectangular $\mathrm{CV}$ curves (Figure $4(\mathrm{a})$ ) in the whole voltage range with weak redox peaks, suggesting its ideal pseudocapacitive properties. The shapes of the $\mathrm{CV}$ curves remain the same with the increase of the sweep rate, indicating the fast charge/discharge property that is desirable for power devices. The results are also in accordance with charge/discharge curves (as shown in Figure 4(b)) which show a triangle shape. The calculated specific capacitance according to the discharge times is shown in Figure 4(c). It reached $60.3 \mathrm{Fg}^{-1}$ at a discharge current density of $0.5 \mathrm{~A} \mathrm{~g}^{-1}$ and still retained $44.5 \mathrm{Fg}^{-1}$ at a large discharge current density of $8 \mathrm{Ag}^{-1}$, showing a good rate capability. The excellent cycle stability at a current density of $0.5 \mathrm{Ag}^{-1}$ is also demonstrated in Figure 4(d). The specific capacitance gradually decreased with increase of the cycle numbers and finally $97.8 \%$ of the specific capacitance is retained after 5000 cycles.

Figure 5 shows Ragone plots of $\mathrm{AC} / / \mathrm{CoP}, \mathrm{AC} / / \mathrm{AC}$, and $\mathrm{AC} / / \mathrm{Co}_{9} \mathrm{~S}_{8}$ capacitors. The $\mathrm{AC} / / \mathrm{CoP}$ asymmetric supercapacitor shows higher energy density $\left(21.3 \mathrm{Wh} \mathrm{kg}^{-1}\right)$ than $\mathrm{AC} / / \mathrm{AC}$ symmetric supercapacitors $\left(4.9 \mathrm{Wh} \mathrm{kg}^{-1}\right)$, which reveals that the application of the $\mathrm{CoP}$ as the positive electrode can improve energy density of the supercapacitor. What is more, the $\mathrm{AC} / / \mathrm{CoP}$ asymmetric supercapacitor also shows higher energy density than $\mathrm{AC} / / \mathrm{Co}_{9} \mathrm{~S}_{8}$ asymmetric supercapacitors $\left(15.1 \mathrm{Wh} \mathrm{kg}^{-1}\right)$ [33], indicating the excellent pseudocapacitive performance and application potentials of the prepared high electrical conductive CoP. The results indicate that the as-prepared high electrical conductive $\mathrm{CoP}$ is an ideal pseudocapacitive material.

\section{Conclusion}

In summary, high electrical conductive $\mathrm{CoP}$ alloys are fabricated through a liquid phase process and a nanoparticles structure with high surface area is obtained. The highest specific capacitance of $286 \mathrm{~F} \mathrm{~g}^{-1}$ is reached at a current density of $0.5 \mathrm{~A} \mathrm{~g}^{-1} .63 .4 \%$ of the specific capacitance is retained when the current density increased 16 times and 98.5\% of the specific capacitance is maintained after 5000 cycles. The AC//CoP asymmetric supercapacitor also shows a high energy density of $21.3 \mathrm{Wh} \mathrm{kg}^{-1}$ and excellent stability $(97.8 \%$ of the specific capacitance is retained after 5000 cycles). The study provides a new strategy for the construction of highperformance energy storage materials by enhancing their intrinsic electrical conductivity. 

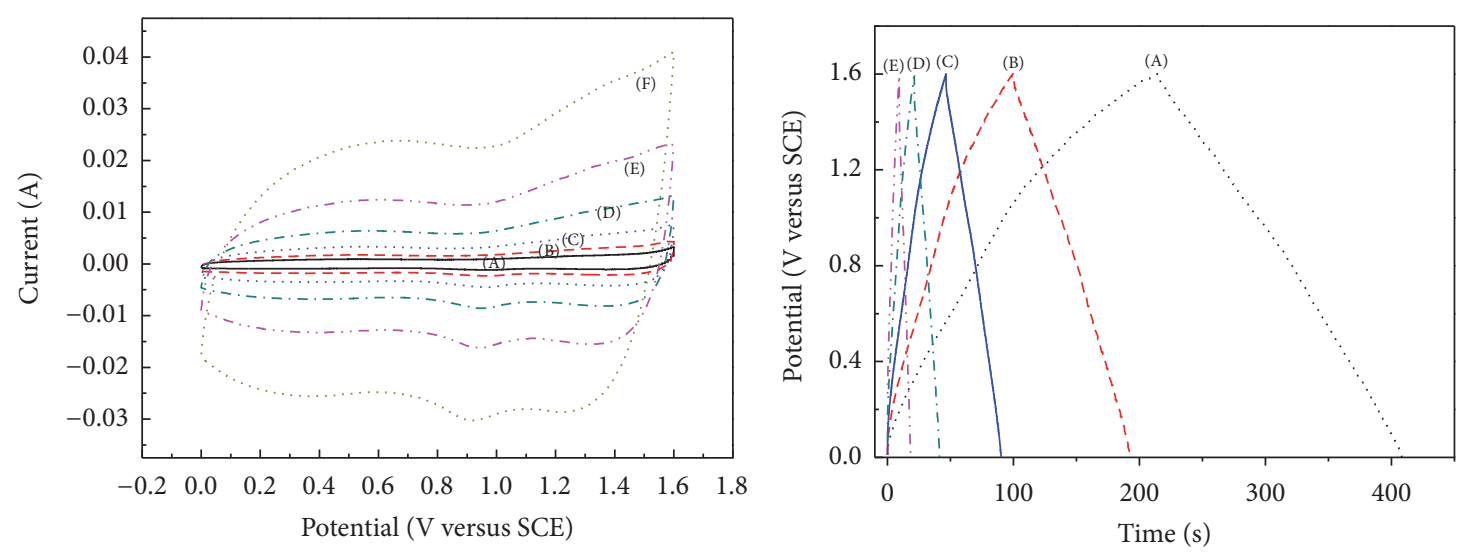
(A) $2.5 \mathrm{mV} \mathrm{s}^{-1}$
(B) $5 \mathrm{mV} \mathrm{s}^{-1}$
(D) $20 \mathrm{mV} \mathrm{s}^{-1}$
(C) $10 \mathrm{mV} \mathrm{s}^{-1}$
(E) $40 \mathrm{mV} \mathrm{s}^{-1}$
(F) $80 \mathrm{mV} \mathrm{s}^{-1}$
(A) $0.5 \mathrm{Ag}^{-1}$
(B) $1 \mathrm{Ag}^{-1}$
(D) $4 \mathrm{Ag}^{-1}$
(C) $2 \mathrm{Ag}^{-1}$
(E) $8 \mathrm{Ag}^{-1}$

(a)

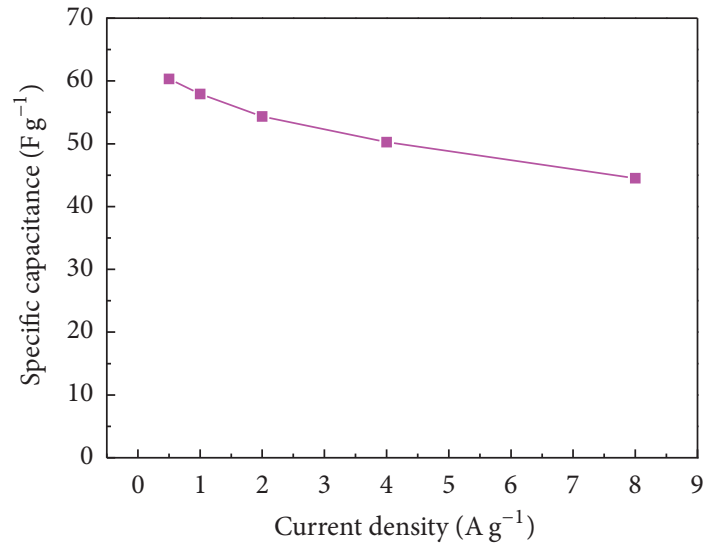

(c) (b)

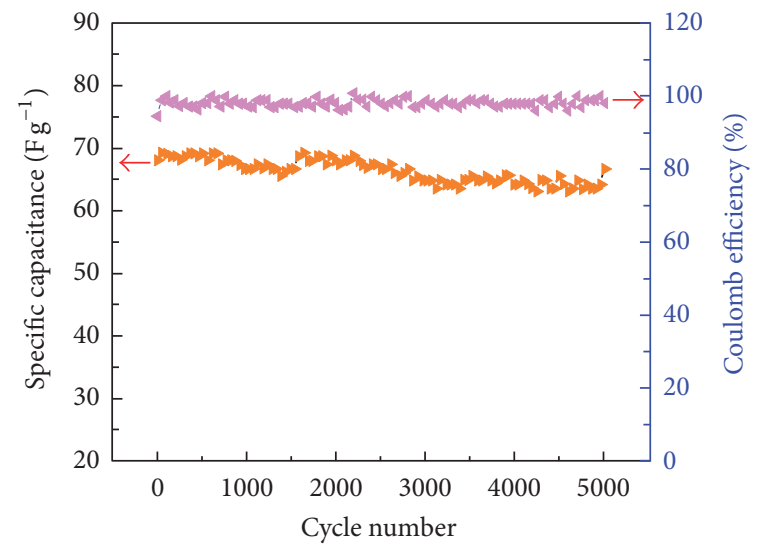

(d)

FIGURE 4: The performance AC//CoP asymmetric supercapacitor. (a) CV curves at different scan rates, (b) charge/discharge curves at various current densities, (c) specific capacitance at different current densities, and (d) cycling stability at $4 \mathrm{~A} \mathrm{~g}^{-1}$.

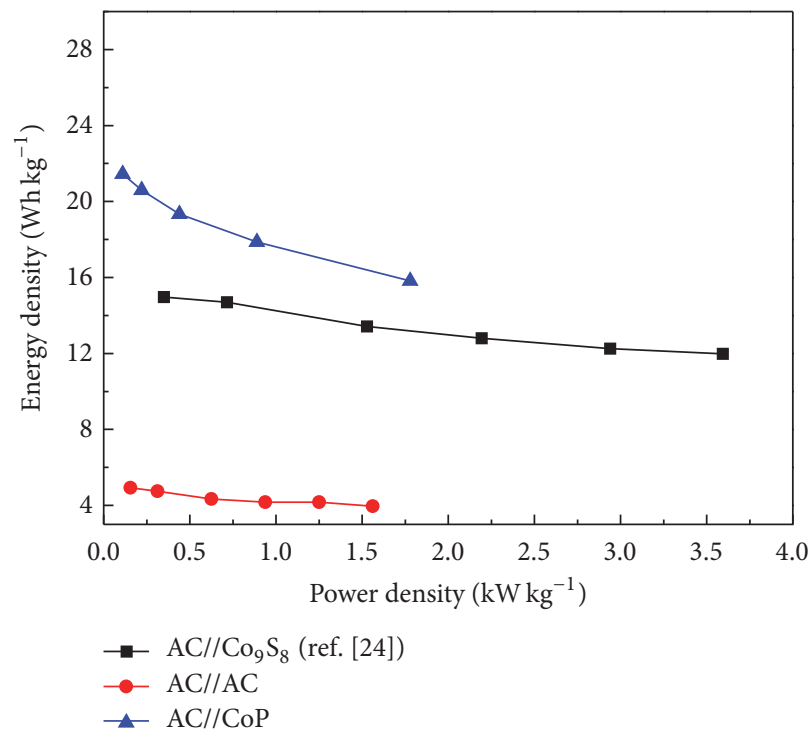

FIgURE 5: Ragone plots of $\mathrm{AC} / / \mathrm{CoP}, \mathrm{AC} / / \mathrm{AC}$, and $\mathrm{AC} / / \mathrm{Co}_{9} \mathrm{~S}_{8}$ capacitors. 


\section{Conflicts of Interest}

The authors declare that they have no conflicts of interest.

\section{Acknowledgments}

This work was supported by the National Natural Science Foundation of China (no. 21403099), the Natural Science Funds for Distinguished Young Scholars of Gansu Province (no. 1606RJDA320), the Opening Foundation of State Key Laboratory of Advanced Processing and Recycling of NonFerrous Metals (SKLAB02015001), and the Research Project of Higher School in Gansu Province (no. 2015B-127).

\section{References}

[1] V. D. Nithya, K. Pandi, Y. S. Lee, and R. K. Selvan, "Synthesis, characterization and electrochemical performances of nanocrystalline $\mathrm{FeVO} 4$ as negative and $\mathrm{LiCoPO} 4$ as positive electrode for asymmetric supercapacitor," Electrochimica Acta, vol. 167, Article ID 24633, pp. 97-104, 2015.

[2] V. Augustyn, P. Simon, and B. Dunn, "Pseudocapacitive oxide materials for high-rate electrochemical energy storage," Energy and Environmental Science, vol. 7, no. 5, pp. 1597-1614, 2014.

[3] C. Zhong, Y. Deng, W. Hu, J. Qiao, L. Zhang, and J. Zhang, "A review of electrolyte materials and compositions for electrochemical supercapacitors," Chemical Society Reviews, vol. 44, no. 21, pp. 7484-7539, 2015.

[4] F.-X. Ma, L. Yu, C.-Y. Xu, and X. W. Lou, "Self-supported formation of hierarchical $\mathrm{NiCo}_{2} \mathrm{O}_{4}$ tetragonal microtubes with enhanced electrochemical properties," Energy and Environmental Science, vol. 9, no. 3, pp. 862-866, 2016.

[5] R. R. Salunkhe, K. Jang, S.-W. Lee, S. Yu, and H. Ahn, "Binary metal hydroxide nanorods and multi-walled carbon nanotube composites for electrochemical energy storage applications," Journal of Materials Chemistry, vol. 22, no. 40, pp. 21630-21635, 2012.

[6] M.-C. Liu, L.-B. Kong, C. Lu, X.-M. Li, Y.-C. Luo, and L. Kang, "A sol-gel process for fabrication of $\mathrm{NiO} / \mathrm{NiCo}_{2} \mathrm{O}_{4} / \mathrm{Co}_{3} \mathrm{O}_{4}$ composite with improved electrochemical behavior for electrochemical capacitors," ACS Applied Materials and Interfaces, vol. 4, no. 9, pp. 4631-4636, 2012.

[7] W. Chen, Z. Fan, L. Gu, X. Bao, and C. Wang, "Enhanced capacitance of manganese oxide via confinement inside carbon nanotubes," Chemical Communications, vol. 46, no. 22, pp. 3905-3907, 2010.

[8] J. Bae, M. K. Song, Y. J. Park, J. M. Kim, M. Liu, and Z. L. Wang, "Fiber supercapacitors made of nanowire-fiber hybrid structures for wearable/flexible energy storage," Angewandte Chemie - International Edition, vol. 50, no. 7, pp. 1683-1687, 2011.

[9] B. E. Conway, "Transition from "supercapacitor" to "battery" behavior in electrochemical energy storage," Journal of the Electrochemical Society, vol. 138, no. 6, pp. 1539-1548, 1991.

[10] P.-C. Chen, G. Shen, Y. Shi, H. Chen, and C. Zhou, "Preparation and characterization of flexible asymmetric supercapacitors based on transition-metal-oxide nanowire/single-walled carbon nanotube hybrid thin-film electrodes," ACS Nano, vol. 4, no. 8, pp. 4403-4411, 2010.

[11] X. Dong, W. Shen, J. Gu et al., "MnO2-embedded-inmesoporous-carbon-wall structure for use as electrochemical capacitors," Journal of Physical Chemistry B, vol. 110, no. 12, pp. 6015-6019, 2006.

[12] W. Sugimoto, H. Iwata, Y. Murakami, and Y. Takasu, "Electrochemical capacitor behavior of layered ruthenic acid hydrate," Journal of the Electrochemical Society, vol. 151, no. 8, pp. A1181A1187, 2004.

[13] M.-S. Wu and P.-C. J. Chiang, "Fabrication of nanostructured manganese oxide electrodes for electrochemical capacitors," Electrochemical and Solid-State Letters, vol. 7, no. 6, pp. A123A126, 2004.

[14] K.-J. Huang, J.-Z. Zhang, and K. Xing, “One-step synthesis of layered $\mathrm{CuS} /$ multi-walled carbon nanotube nanocomposites for supercapacitor electrode material with ultrahigh specific capacitance," Electrochimica Acta, vol. 149, pp. 28-33, 2014.

[15] J. Jiang, Y. Li, J. Liu, X. Huang, C. Yuan, and X. W. Lou, "Recent advances in metal oxide-based electrode architecture design for electrochemical energy storage," Advanced Materials, vol. 24, no. 38, pp. 5166-5180, 2012.

[16] K. Xu, X. Yang, J. Yang, and J. Hu, "Synthesis of hierarchical $\mathrm{Co}_{3} \mathrm{O}_{4} @ \mathrm{NiCo}_{2} \mathrm{O}_{4}$ core-shell nanosheets as electrode materials for supercapacitor application," Journal of Alloys and Compounds, vol. 700, pp. 247-251, 2017.

[17] Q. Chen, D. Cai, and H. Zhan, "Construction of reduced graphene oxide nanofibers and cobalt sulfide nanocomposite for pseudocapacitors with enhanced performance," Journal of Alloys and Compounds, vol. 706, pp. 126-132, 2017.

[18] S. Chen, M. Xue, Y. Li, Y. Pan, L. Zhu, and S. Qiu, "Rational design and synthesis of $\mathrm{NixCo}_{3}-\mathrm{xO}_{4}$ nanoparticles derived from multivariate MOF-74 for supercapacitors," Journal of Materials Chemistry A, vol. 3, no. 40, pp. 20145-20152, 2015.

[19] W. Yu, X. Jiang, S. Ding, and B. Q. Li, "Preparation and electrochemical characteristics of porous hollow spheres of $\mathrm{NiO}$ nanosheets as electrodes of supercapacitors," Journal of Power Sources, vol. 256, pp. 440-448, 2014.

[20] M. Huang, Y. Zhang, F. Li, L. Zhang, Z. Wen, and Q. Liu, "Facile synthesis of hierarchical $\mathrm{Co}_{3} \mathrm{O}_{4} @ \mathrm{MnO}_{2}$ core-shell arrays on $\mathrm{Ni}$ foam for asymmetric supercapacitors," Journal of Power Sources, vol. 252, pp. 98-106, 2014.

[21] W. Zhou, J. Liu, T. Chen et al., "Fabrication of $\mathrm{Co}_{3} \mathrm{O}_{4}$-reduced graphene oxide scrolls for high-performance supercapacitor electrodes," Physical Chemistry Chemical Physics, vol. 13, no. 32, pp. 14462-14465, 2011.

[22] M. Dai, L. Song, J. T. Labelle, and B. D. Vogt, "Ordered mesoporous carbon composite films containing cobalt oxide and vanadia for electrochemical applications," Chemistry of Materials, vol. 23, no. 11, pp. 2869-2878, 2011.

[23] S. Zhang, H. Gao, M. Huang, and J. Zhou, "One-step hydrothermal synthesis of nitrogen doping graphene based cobalt oxide and its supercapacitive properties," Journal of Alloys and Compounds, vol. 705, pp. 801-805, 2017.

[24] T. Battumur, S. B. Ambade, R. B. Ambade et al., "Addition of multiwalled carbon nanotube and graphene nanosheet in cobalt oxide film for enhancement of capacitance in electrochemical capacitors," Current Applied Physics, vol. 13, no. 1, pp. 196-204, 2013.

[25] Y.-M. Hu, M.-C. Liu, Y.-X. Hu et al., "Design and synthesis of $\mathrm{Ni}_{2} \mathrm{P} / \mathrm{Co}_{3} \mathrm{~V}_{2} \mathrm{O}_{8}$ nanocomposite with enhanced electrochemical capacitive properties," Electrochimica Acta, vol. 190, pp. 10411049, 2016.

[26] M. Zhi, C. Xiang, J. Li, M. Li, and N. Wu, "Nanostructured carbon-metal oxide composite electrodes for supercapacitors: a review," Nanoscale, vol. 5, no. 1, pp. 72-88, 2013. 
[27] Y. Hu, M. Liu, Q. Yang, L. Kong, and L. Kang, "Facile synthesis of high electrical conductive CoP via solid-state synthetic routes for supercapacitors," Journal of Energy Chemistry, vol. 26, no. 1, pp. 49-55, 2017.

[28] Z. Zhang, J. Yang, Y. Nuli, B. Wang, and J. Xu, "CoPx synthesis and lithiation by ball-milling for anode materials of lithium ion cells," Solid State Ionics, vol. 176, no. 7-8, pp. 693-697, 2005.

[29] Y.-H. Cui, M.-Z. Xue, Z.-W. Fu, X.-L. Wang, and X.-J. Liu, "Nanocrystalline CoP thin film as a new anode material for lithium ion battery," Journal of Alloys and Compounds, vol. 555, pp. 283-290, 2013.

[30] X. Chen, M. Cheng, D. Chen, and R. Wang, "Shape-Controlled Synthesis of $\mathrm{Co}_{2} \mathrm{P}$ Nanostructures and Their Application in Supercapacitors," ACS Applied Materials and Interfaces, vol. 8, no. 6, pp. 3892-3900, 2016.

[31] X. Yang, A.-Y. Lu, Y. Zhu et al., "CoP nanosheet assembly grown on carbon cloth: A highly efficient electrocatalyst for hydrogen generation," Nano Energy, vol. 15, pp. 634-641, 2015.

[32] K. Chen, X. Huang, C. Wan, and H. Liu, "Efficient oxygen reduction catalysts formed of cobalt phosphide nanoparticle decorated heteroatom-doped mesoporous carbon nanotubes," Chemical Communications, vol. 51, no. 37, pp. 7891-7894, 2015.

[33] B. Li, Y. Hu, J. Li et al., "Mechanical alloying synthesis of Co9S8 particles as materials for supercapacitors," Metals, vol. 6, no. 6, article no. 142, 2016. 

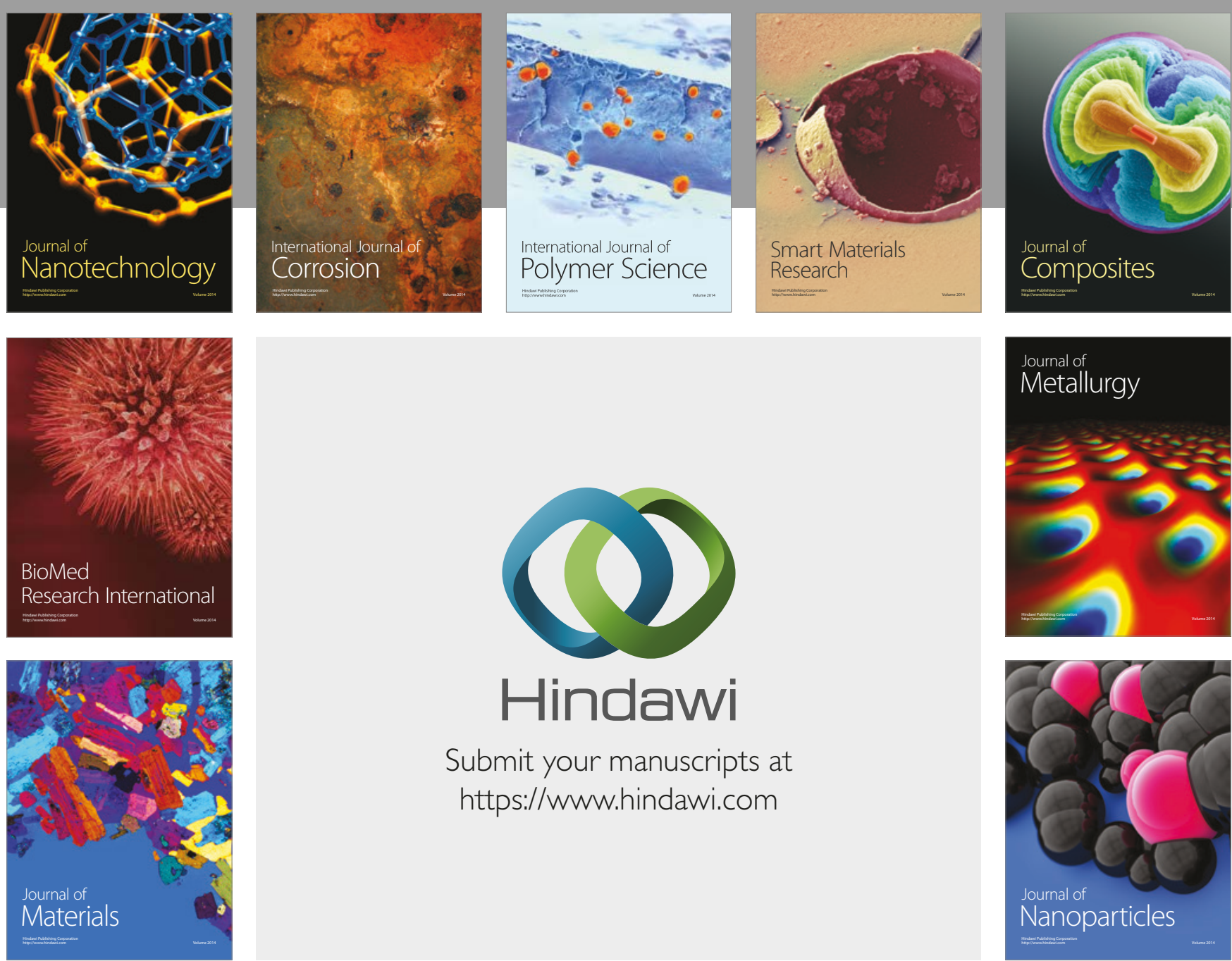

\section{Hindawi}

Submit your manuscripts at

https://www.hindawi.com
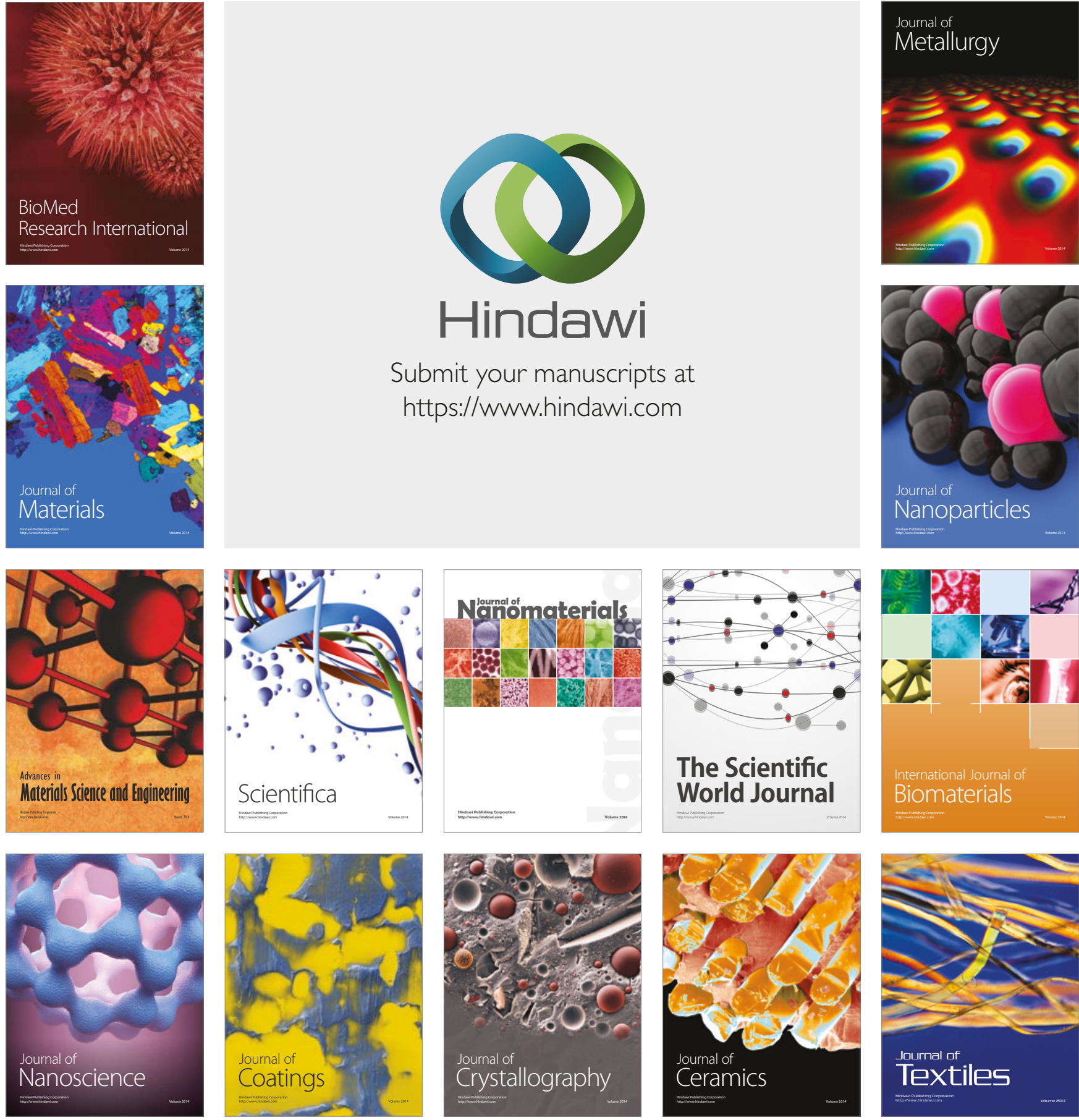

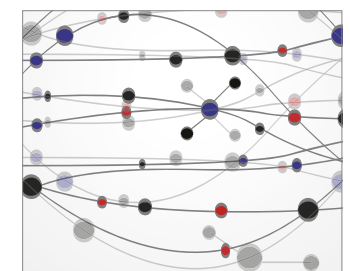

The Scientific World Journal
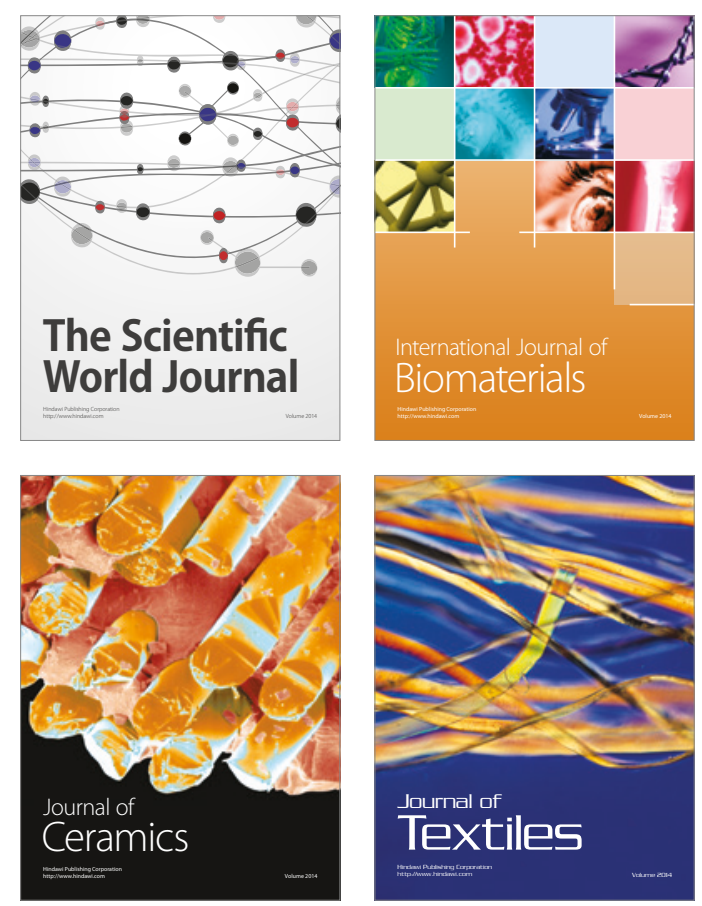